\title{
Trends in Kaposi sarcoma prevalence at HIV care initiation in adults at a large HIV treatment program in Jos, Nigeria
}

Maxwell 0 Akanbi ( $\square$ maxwell_akanbi@yahoo.com )

Northwestern University Feinberg School of Medicine https://orcid.org/0000-0001-6022-2359

Lucy. A. Bilaver

Northwestern University Feinberg School of Medicine

Chad Achenbach

Northwestern University Feinberg School of Medicine

Lisa. R. Hirschhorn

Northwestern University Feinberg School of Medicine

Olugbenga A Silas

College of Human Sciences, University of Jos

\section{Patricia. A. Agaba}

College of Health Sciences, University of Jos

\section{Oche Agbaji}

College of Health Sciences, University of Jos

Nathan Y. Shehu

College of Health Sciences, University of Jos

Simji. S. Gomerep

College of Health Sciences, University of Jos

\section{Solomon A. Sagay}

College of Health Sciences, University of Jos

\section{Lifang Hou}

Northwestern University Feinberg School of Medicine

Robert. L. Murphy

Northwestern University Feinberg School of Medicine

\section{Research Article}

Keywords: HIV-associated Kaposi sarcoma, HIV-associated malignancies, Africa, Nigeria, antiretroviral therapy, epidemiology

Posted Date: April 15th, 2020 
DOI: https://doi.org/10.21203/rs.3.rs-22521/v1

License: (c) (1) This work is licensed under a Creative Commons Attribution 4.0 International License. Read Full License 


\section{Abstract}

Background: Improved access to antiretroviral therapy (ART) significantly reduced the prevalence of Kaposi Sarcoma (KS) among patients initiating care for Human Immunodeficiency Virus (HIV) care in western nations. A similar pattern has not been universally documented across sub-Saharan Africa where the majority of people with HIV reside. This study examined trends in KS prevalence among adults initiating HIV care in Nigeria from 2006 to 2017.

Methods: Data of patients 18 years or older, who initiated HIV care at the Jos University Teaching Hospital HIV clinic Jos, Nigeria from 2006 and 2017, were analyzed. Prevalence of KS over three consecutive four-year periods of increased ART coverage: 2006-2009, 2010-2013 and 2014-2017 were estimated. Logistic regression models were used to compare age- and sex-adjusted trends in KS prevalence rates at HIV care initiation over the three-time periods, and determine independent predictor of KS.

Results: Among 16,431 adults who initiated HIV care from January 2006 to Decemeber 2017, mean age 35.1 (9.5) years, $65.7 \%$ female, and $51.1 \%$ with CD 4 T-cell count $<200$ cells $/ \mathrm{mm}^{3}$; the overall prevalence of $\mathrm{KS}$ was $0.59 \%(95 \% \mathrm{Cl} 0.48-0.72)$. KS prevalence was lowest at the time of HIV care initiation from 2006-2009 (0.39\%; 95\% Cl 0.29-0.53), peaked at 1.12\% (95\% Cl 0.82-1.52) from 2010-2013 and declined to $0.72 \%$ (95\% Cl 0.42-1.20) from 2014-2017. Compared to 2006-2009, age- and sex-adjusted odds for KS were 2.81 (95\% Cl 1.83-4.34, $\mathrm{p}<0.01$ ) for 2010-2013 and 1.74 (95\% Cl 0.95-3.30, $\mathrm{p}=0.07$ ) for 2014-2017. Independent predictors of KS were period of enrollment, male sex and low CD4 T-cell count.

Conclusion: Expansion of ART access was not associated with a decline in KS prevalence among adults initiating ART in Nigeria.

\section{Introduction}

Despite over a decade of antiretroviral therapy (ART), Kaposi Sarcoma (KS) has remained a major cause of morbidity and mortality in sub-Saharan Africa (SSA)[1, 2]. In 2018, about 42,000 incident cases and 20,000 deaths linked to KS occurred worldwide[1]; of these, about $60 \%$ of the incident cases and $90 \%$ deaths occurred in SSA[1]. KS in adults with the human immunodeficiency virus (HIV) enrolling in care (prevalence KS), has been a major source of KS in SSA[3]. Despite ART, adults starting ART with KS have a high mortality risk, higher risk of loss-to-follow-up and have a poorer immunologic response, compared to those without $\mathrm{KS}[4,5]$. KS occurring before ART initiation also tends to be more severe, necessitating chemotherapy or radiotherapy, which increases the cost of care[6, 7]. Moreover, KS in people initiating HIV care implies that presentation to care is late[8], indicative of a failure of interventions aimed at increasing access to HIV care through timely HIV diagnosis and linkage to care. So monitoring trends in KS among patients initiating ART could provide a useful insight into the success of HIV control.

With about 1.9 million people living with HIV in 2018, Nigeria, the most populated country in sub-Saharan Africa (SSA), had the second-largest HIV epidemic in the world[9, 10]. Various studies have reported high 
seroprevalence (42-62\%) of human herpesvirus-8 (HHV-8), a virus etiologically linked to KS, among adults with HIV in Nigeria [11, 12], and the few available studies indicate that about $2 \%$ of adults with HIV in Nigeria have KS[13, 14]. ART became publicly available in Nigeria in 2002 and reported ART coverage increased from 4\% in 2004 to 55\% in 2017[15]. Despite this remarkable increase, ART coverage in Nigeria lags behind those of other countries with high HIV prevalence[16]. Similar to other countries in SSA, Nigeria has routinely adopted updated World Health Organization (WHO) HIV treatment guidelines, which have continuously expanded ART access by recommending earlier ART initiation[10, 17]. Besides, ART which was initially only provided at specialized HIV treatment centers in hospitals in major cities became decentralized starting in 2007, providing access to ART in health facilities in communities closer to patients[18]. The implementation of these strategies has increased access to ART over the past decade. It is, however, unclear if these interventions were effective in reducing the prevalence of KS in adults initiating ART.

Utilizing longitudinal data from one of Nigeria's largest HIV clinical cohorts, we aimed to describe trends in KS among adults who initiated HIV care from 2006 to 2017 in Jos, Nigeria and identify independent predictors of KS.

\section{Methods}

\section{Study design \& setting}

We conducted a retrospective cohort study among adults who initiated HIV care at the Jos University Teaching Hospital (JUTH) HIV clinic from January $1^{\text {st, }} 2006$ to December $31^{\text {st, }} 2017$. JUTH is a tertiary health facility in north-central Nigeria. The JUTH HIV clinic commenced patient enrollment in 2002 and by December 2017, it had provided care to over 30,000 persons with HIV. HIV care was supported by funding from the Government of Nigeria, Bill and Melinda Gates Foundation, and the United States President's Emergency Plan for AIDS Relief (PEPFAR) fund[19, 20]. The JUTH HIV program implemented decentralized HIV care in 2007, through a 'hub and spoke model', providing people with new HIV diagnosis the option to enroll for long term HIV care either at the JUTH HIV clinic or at affiliated HIV treatment facilities spread throughout Plateau State[18]. Only patients enrolled for long-term HIV care at the JUTH HIV clinic were included in this study.

\section{HIV Care and treatment}

The clinic provided comprehensive HIV care which included free ART to all eligible patients, routine CD4-T cell count and HIV viral load measurement (for patients on ART), as well as treatment of opportunistic infections. ART eligibility was based on the Nigerian ART Treatment Guidelines[9, 21]. The 2005 guideline for HIV treatment in Nigeria was in effect from 2006 to 2010[9] and it recommended ART in adults with CD4 T-cell count $\leq 200 \mathrm{cell} / \mathrm{mm}^{3}$ or World Health Organization (WHO) stage 4 or WHO stage 3 with CD 4 T-cell count $<350$ cells $/ \mathrm{mm}^{3}$. In 2010 eligibility for ART was extended to adults with CD4 T-cell count < 350 cells $/ \mathrm{mm}^{3}$ irrespective of WHO clinical stage of HIV/AIDS or the presence of WHO stage 3 or 4 
HIV/AIDS disease[21]. Patients with HIV nephropathy and discordant couples were also eligible for ART irrespective of CD4 T-cell count[21]. In 2014, ART eligibility was further expanded to patients with a CD4 Tcell count $<500$ cells $/ \mathrm{mm}^{3}$, HIV neuropathy, or co-infection with hepatitis B virus[9]. All HIV positive pregnant women were also eligible for life long ART [9]. Starting in 2016, all patients with HIV, irrespective of CD4 T-cell count, were eligible for ART [9].

\section{Kaposi Sarcoma diagnosis}

As per the clinic protocol, KS diagnosis was clinical, and histologic confirmation requested when the diagnosis was uncertain or for patients with advanced KS who required chemotherapy or additional therapy for KS apart from ART. Tissue biopsy was usually done on-site, while histology was usually done at the histology department within the hospital. Diagnosis or treatment of KS was not routinely covered by the HIV treatment program, so patients needed to pay out-of-pocket.

\section{Participants and Data Sources}

Patients were included in the study if they had a confirmed HIV diagnosis, were 18 years or older at the first clinic visit, and had no history of prior ART use. Data of patients with only one clinic visit record were excluded because at least 2 visits were required to complete evaluation for clinic enrollment. We obtained data from the electronic medical record (EMR) of the JUTH HIV clinic. During all patient encounters, data were collected using standardized forms and transferred into the EMR. Pharmacy records and laboratory results were also uploaded in the EMR and merged with patients' clinical records. Information within the database included demographic data obtained at the initial visit, diagnosis of AIDS-defining conditions (including KS), ART history and results of all laboratory tests, including CD4-T cell count, which were carried out on site. All new patients had an assessment, which was captured and stored in the EMR in an 'Initial Assessment Form'. This captured visit date, demographic information, WHO stage of HIV disease, presence of any listed AIDS-defining conditions including KS (Yes/No), prior ART exposure (Yes/No) and results of CD 4 T-cell count. Because results of CD 4 -T cell count were not available immediately, patients were asked to return within two to our weeks to complete the Initial Assessment Form. This Initial Assessment Form was the primary source of data for this study.

\section{Study Variables}

The outcome of this study, prevalent KS, was defined as KS diagnosed at the first clinic visit or within 30 days of the first visit[22]. The exposure variable, the period of initiation of HIV care, was categorized into three consecutive periods of four years representing different eras of ART eligibility expansion in Nigeria; 2006-2009, 2010-2013, and 2014-2017. Based on previous research, the following factors known to influence risk for KS and were available in the EMR were included as covariates: age at initiation of HIV care[23, 24], sex[25], HIV-risk factor[26], and CD4 T-cell count at the time of HIV diagnosis(baseline CD4 Tcell count)[6,27]. Age and baseline CD4 -Tcell count was analysed as a continuous and categorical variable. Age was categorized into three groups ( $<30,30-39, \geq 40$ years); while CD4 T-cell count had four categories representing the severity of immunosuppression $(<200,200-349,350-400$ and $\geq 500$ 
cells $/ \mathrm{mm}^{3}$ ). Sex had two categories (male or female). The main risk for HIV transmission was captured as: heterosexual relationship, blood transfusion, intravenous drug use, men who have sex with men and unknown.

\section{Statistical Analyses}

Descriptive statistics of the study sample were generated. Continuous variables with normal distribution were summarized as means (Standard Deviation [SD]), while continuous variables with skewed distribution were summarized as median (Interquartile Range (IQR)). Categorical variables were presented as counts (percentages; \%). We performed comparisons of characteristics of patients with and without KS using the Student's t-test for normally distributed continuous variables, Mann-Whitney U test for skewed continuous variables and the chi-squared test for categorical variables.

Crude prevalence of KS was calculated by dividing the number of patients with KS by the number of patients who initiated HIV care during that period and presented as percentages (95\% confidence interval). Crude prevalence of KS during the three periods (2006-2009, 2010-2013, and 2014-2017) and prevalence by sex was computed. Trends in KS prevalence, over the three periods, were examined using the Chi-squared trend test.

Independent predictors of prevalent KS were evaluated using logistic regression models. To minimize bias due to missing variables, the multiple imputation method was used to impute missing baseline CD 4 T-cell count, the only covariate with missing values. The multiple imputation method used the distribution of observed data to generate multiple plausible values of the missing baseline CD 4 T-cell values to create multiple complete datasets. Each dataset was then analysed to get a set of estimates which were then combined using the method proposed by Rubin[28] to obtain an overall estimate, which was used in subsequent logistic regression analyses. After the bivariate logistic regression, variables were included in the adjusted model if they had $\mathrm{p}<0.2$ in the bivariate model or if they are known predictors of KS based on prior research. The goodness of fit of the final model was determined using the Likelihood ratio Chisquared statistics. With the results of the fully adjusted model, margin plots were generated to display the relationship between baseline CD4 T-cell count and the prevalence of KS, stratified by sex.

All statistical analyses were carried out using Stata Statistical Software: Release 14. College Station, TX: Stata Corp LP. In all analyses, a two-sided $p<0.05$ was considered significant.

\section{Results}

Data of 16,431 out of 19,301 patients in the adult HIV clinic, who initiated HIV care from January $1^{\text {st }}$, 2006 to December $31^{\text {st }}$, were analyzed. Records of 81 patients $<18$ years at the time of clinic enrollment and 2,606 with only one clinic visit record were excluded. The mean age of the 16,431 adults was 35.1 (9.5) years and the majority (10,788; 65.7\%) were female. The median baseline CD4 T-cell count was 201 (IQR 89-332) cells $/ \mathrm{mm}^{3}$. Table 1 summarizes patient characteristics categorized by the period of initiation of HIV care. 
Table 1: Characteristics of adults who initiated HIV care between 2006 and 2017 in Jos, Nigeria 


\begin{tabular}{ccccc}
\hline & Total & $2006-2009$ & $2010-2013$ & $2014-2017$ \\
& $(\mathrm{~N}=16,431)$ & $(\mathrm{N}=10,911)$ & $(\mathrm{N}=3,563)$ & $(\mathrm{N}=1,957)$ \\
Age, years, means (SD) & $35.1(9.5)$ & $34.9(9.3)$ & $35.2(9.5)$ & 35.9
\end{tabular}

Age group, years, n (\%)

$\begin{array}{lrrrr}<30 & 5,025 & 3,368 & 1,104 & 553(28.3) \\ & (30.6) & (30.9) & (31.0) & \\ 30-39 & 6,598 & 4,465 & 1,399 & 734(37.5) \\ & (40.2) & (40.9) & (39.3) & \\ \geq 40 & 4,808 & 3,078 & 1,060 & 670(34.2) \\ & (29.3) & (28.2) & (29.8) & \end{array}$

Sex, n (\%)

$\begin{array}{ccccc}\text { Female } & 10,788 & 7,285 & 2,291 & 1,212 \\ & (65.7) & (66.8) & (64.3) & (61.9) \\ \text { Male } & 5,643 & 3,626 & 1,272 & 745(38.1) \\ & (34.3) & (33.2) & (35.7) & \end{array}$

Risk for HIV

\begin{tabular}{|c|c|c|c|c|}
\hline Heterosexual & $\begin{array}{c}16,155 \\
(98.3)\end{array}$ & $\begin{array}{c}10,743 \\
(98.5)\end{array}$ & $\begin{array}{l}3,381 \\
(97.7)\end{array}$ & $\begin{array}{l}1,931 \\
(98.7)\end{array}$ \\
\hline Blood transfusion & $184(1.1)$ & $152(1.4)$ & $19(0.5)$ & $13(0.7)$ \\
\hline Others $^{\mathrm{a}}$ & $92(0.56)$ & $16(0.2)$ & $63(1.8)$ & $13(0.7)$ \\
\hline CD4, cells $/ \mathrm{mm}^{3}$, Median & $\begin{array}{c}201(89- \\
332)\end{array}$ & $\begin{array}{c}192(84- \\
320)\end{array}$ & $\begin{array}{c}215(98- \\
344)\end{array}$ & $\begin{array}{c}222(94- \\
353)\end{array}$ \\
\hline
\end{tabular}

Baseline CD4-T-cell count, cells $/ \mathrm{mm}^{3}$, n (\%)

$\begin{array}{ccccc}<200 & 8,393 & 5,851 & 1,660 & 884(45.2) \\ & (51.1) & (53.6) & (46.6) & \\ 200-349 & 3,628 & 2,393 & 796(22.3) & 439(22.4) \\ & \text { Page } 8 / 20 & & & \end{array}$



(22.1)
(21.9)

350-499

1,550 (9.4)

999 (9.2)

349 (9.8)

202 (10.3)

$\geq 500$

1,213 (7.4)

775 (7.1)

276 (7.8)

162 (8.3)

Missing

1,645

893 (8.2)

482 (13.5)

270 (13.8)

(10.0)

a

HIV: Human Immunodeficiency Virus; SD: Standard Deviation, IQR: Interquartile Range; ${ }^{\text {a Includes }}$ intravenous drug use, men who have sex with men and unknown; ${ }^{b}$ missing CD4 T-cell counts computed using multiple imputation method

A total of 97 cases KS were documented, with an overall prevalence of $0.59 \%$ (95\% $\mathrm{Cl} 0.48-0.72)$. Thirtythree cases (34\%) of KS were histologically confirmed. Table 2 shows the prevalence of KS by the period of initiation of HIV care and sex. KS prevalence varied significantly across the three time-periods, with a significant upward, 12.14, $\mathrm{p}<0.01)$. The period with the highest prevalence of KS was 2010-2013 (1.12\%), while the lowest was $2006-2009$ (0.39\%). The prevalence of KS was also consistently higher in males than in females.

Table 2: Prevalence of Kaposi sarcoma among adults at the initiation of HIV care at the Jos University Teaching Hospital Jos, Nigeria (2006-2017)

\begin{tabular}{cccc}
\hline Period of initiation of HIV care & \multicolumn{3}{c}{ Kaposi Sarcoma prevalence, percent (95\% CI) } \\
\hline \multirow{2}{*}{$2006-2017$} & Total population & Male & Female \\
$2006-2009$ & $0.59(0.48-0.72)$ & $0.92(0.70-1.21)$ & $0.41(0.31-0.56)$ \\
$2010-2013$ & $0.39(0.29-0.53)$ & $0.63(0.42-0.95)$ & $0.27(0.18-0.42)$ \\
$2014-2017$ & $1.12(0.82-1.52)$ & $1.49(0.95-2.33)$ & $0.91(0.60-1.40)$ \\
\hline
\end{tabular}

HIV: Human Immunodeficiency Virus

Compared to 2006-2009, age- and sex-adjusted odds for KS were 2.81 higher (95\% Cl 1.83-4.34, $p<0.01$ ) in 2010-2013. Although the odds for KS was higher in 2014-2017, compared to 2006-2009, the difference was not statistically significant (OR $1.74,95 \% \mathrm{Cl} 0.95-3.30, \mathrm{p}=0.07$ ). The variation in $\mathrm{KS}$ prevalence across the three time periods, after adjusting for age and sex is shown in Figure1. The trend is similar to the result obtained from the crude prevalence. 
Table 3 compares patients with KS to those without KS free at the time of initiation of HIV care. Male sex and lower baseline CD4-T cell count were associated with KS diagnosis. There was also a trend for patients with KS to be older, but this did not reach statistical significance.

Table 3: Characteristics of adults who initiated HIV care at the Jos University Teaching Hospital HIV Clinic Jos, Nigeria by Kaposi sarcoma Status (2006-2017)

\begin{tabular}{|c|c|c|c|}
\hline & \multicolumn{2}{|c|}{$\begin{array}{c}\text { Kaposi sarcoma (KS) status at initiation } \\
\text { of care }\end{array}$} & \multirow[t]{2}{*}{$\begin{array}{c}\mathrm{p}- \\
\text { value }\end{array}$} \\
\hline & $\begin{array}{l}\text { Prevalent KS } \\
\qquad \mathrm{n}=97\end{array}$ & $\begin{array}{c}\text { KS-Free } \\
\mathrm{n}=16,334\end{array}$ & \\
\hline Age, years, means (SD) & $36.5(0.1)$ & $35.1(0.9)$ & 0.13 \\
\hline Age group, years, n (\%) & & & 0.06 \\
\hline$<30$ & 19 (19.6) & $5,006(30.7)$ & \\
\hline $30-39$ & $44(45.4)$ & $6,554(40.1)$ & \\
\hline$\geq 40$ & $34(35.0)$ & $4,774(29.2)$ & \\
\hline Sex, n (\%) & & & $<0.01$ \\
\hline Female & $45(46.4)$ & $10,743(65.8)$ & \\
\hline Male & $52(53.6)$ & $5,591(34.2)$ & \\
\hline Risk for HIV & & & 0.35 \\
\hline Heterosexual & 97 (100) & $16,058(98.3)$ & \\
\hline $\begin{array}{l}\text { Baseline CD4, cells } / \mathrm{mm}^{3}, \text { Median } \\
(\mathrm{IQR})^{\mathrm{a}}\end{array}$ & $162(67-326)$ & $202(89-332)$ & $<0.01$ \\
\hline $\begin{array}{l}\text { Baseline CD4-T-cell count, cells } / \mathrm{mm}^{3} \text {, } \\
\text { n (\%) }\end{array}$ & & & 0.09 \\
\hline$<200$ & $65(69.2)$ & $8,330(51.0)$ & \\
\hline $200-349$ & $17(18.1)$ & $3,611(22.1)$ & \\
\hline $350-499$ & $8(8.5)$ & $1,542(9.4)$ & \\
\hline$\geq 500$ & $4(4.3)$ & $1,209(7.4)$ & \\
\hline Missing & $3(3.1)$ & $1,643(10.1)$ & \\
\hline
\end{tabular}


HIV: Human Immunodeficiency Virus; SD: Standard Deviation, IQR: Interquartile Range, ${ }^{a}$ Missing values imputed using the multiple imputation method

Results from the multivariate logistic regression models showed that prevalent KS was independently associated with the period of enrollment, sex and CD4 T-cell count (Table 4).

Table 4: Logistic regression models of factors associated with prevalent Kaposi sarcoma at the time of HIV care initiation in adults at the Jos University Teaching Hospital HIV Clinic, Jos, Nigeria (2006-2017) 


\section{Characteristics}

\section{Unadjusted Analysis Adjusted Analysis}

OR $(95 \%$ CI) P- $\quad$ OR $(95 \% \quad$ P-

value $\quad \mathrm{CI}) \quad$ value

Year of initiation of HIV care

2006-2009

2010-2013

2014-2017

Male

Female

Age, per 10 year increase
Reference

1.76 (1.03-

3.03)

$\geq 40$

a Baseline CD4 T-cell count, per 100

cells $/ \mathrm{mm}^{3}$ increase

$\begin{array}{cccc}\text { Reference } & & \text { Reference } & \\ 2.87(1.88- & <0.01 & 2.88(1.87- & <0.01 \\ 4.42) & & 4.45) & \\ 1.82(0.99- & 0.05 & 1.80(0.98- & 0.06 \\ 3.34) & & 3.30) & \end{array}$

Reference Reference

$0.45(0.30-\quad<0.01 \quad 0.52(0.34-\quad<0.01$

0.67)

$0.80)$

$1.16(0.95-\quad 0.13$

1.42)

Age group, years

$<30$
$30-39$
$\geq 40$
ell count, per 100

1.87 (1.07-

0.03

3.29)

$0.04 \quad 1.45$ (0.84-

0.18

2.52)

$0.85(0.74-\quad 0.02$

$0.87(0.76-$

0.04

0.97)

0.99)

OR: Odds ratio;

Compared to 2006-2009, the adjusted odds for KS were higher among patients who enrolled in care from 2010-2013, but not 2014-2017. Odds for KS were 53\% lower in females compared to males and every 100 cells $/ \mathrm{mm}^{3}$ increase in CD4-Tcell count was associated with a $14 \%$ decrease in odds for KS. Although people older than 30 years had higher odds for KS in the univariate analysis, this association was not statistically significant in the fully adjusted model. Margins plots of the predicted KS prevalence based on 
CD4 T-cell count stratified by sex are shown in Figure 2. There was an inverse relationship between CD4 Tcell count and prevalent KS. Although men had a higher risk for KS compared to women at all CD4 T-cell counts, the difference in KS risk was not significantly different at very low CD 4 T-cell counts $(\leq 100$ cell $/ \mathrm{mm}^{3}$ ) and normal CD 4 T-cell counts $\left(>500\right.$ cells $\left./ \mathrm{mm}^{3}\right)$.

\section{Discussion}

Despite the increase in ART coverage in Nigeria from 4\% in 2004 to 55\% in 2017[15], we did not observe a consistent decline in the prevalence of KS among adults who initiated in HIV care at this large HIV treatment facility in Jos, Nigeria. Compared to the baseline period (2006-2009), the age- and sex-adjusted prevalence of KS was nearly three times higher in the subsequent period (2010-2013; OR 2.81, 95\% Cl 1.82-4.34). Although the prevalence of KS subsequently declined in the most recent period (2014-2017), it remained higher, but not statistically different, from the baseline period. Overall, men had $53 \%$ higher odds of presenting with KS compared to women, and the odds for having KS at initial presentation declined by $13 \%$ for every 100 cells $/ \mathrm{mm}^{3}$ increase in baseline CD4 T-cell count.

The reason for the higher prevalence of KS in 2010-2014 compared to 2006-2009 is unclear. Given the increase in ART coverage in the country, the marginally higher median CD4 T-cell in 2010-2014 compared to 2006-2009, and the known inverse relationship between CD4 T-cell count and KS, the higher prevalence of KS in 2010-2014 was unexpected. While this increase in KS prevalence may be due to the ineffectiveness of interventions to address the burden of HIV and its co-morbidities, this may not always be the case[2, 29]. In a Ugandan cohort, an increase in KS prevalence during a period of ART expansion was attributed to a clinical trial for which patients with KS were actively recruited[2]. That was however not the case in the present cohort. Paradoxically, increased ART coverage may lead to a transient increase in KS prevalence at enrollment, as sick patients from previously unreached communities gain access to HIV care[29]. Community-based studies would be needed to evaluate this hypothesis. Irrespective of the cause, the trend is troubling and calls for continuous routine monitoring of KS burden in patients initiating HIV care.

An important driver of KS risk in this population was the late initiation of HIV care. In the present cohort, $73 \%$ of patients had a baseline CD 4 T-cell count below 350 cells $/ \mathrm{mm}^{3}$, thereby meeting the case definition for late presentation for HIV care[8]. Using the full definition for late presentation which includes the presence of an AIDS-defining event, the proportion of patients presenting late was above $80 \%$. An earlier study in this HIV cohort similarly showed that over $80 \%$ of patients initiating HIV care between 2005 and 2010 presented late, with a marginal decline from $88.9 \%$ in 2005 to $80.1 \%$ in 2010[13]. While late presentation to care has been reported in HIV cohorts in various countries, its burden is greater in lowand middle-income countries, compared to high-income countries[30,31]. Due to the high seroprevalence of HHV-8 among adults with HIV in Nigeria[11, 12], timely HIV diagnosis and linkage to care may be the only viable intervention to significantly reduce the prevalence of KS in adults initiating HIV care. 
Several studies have reported a higher risk of HIV-associated KS in males compared to females[22-24, 32]. In North America and Europe cohorts, it was attributed to the risk of co-transmission of HIV and HHV8 through sex in men who had sex with men (MSM), who constituted the largest HIV risk group[32-35]. In Nigeria and most of SSA, heterosexual sexual activity is the major route of HIV transmission, yet many studies have reported a higher KS prevalence in males, suggesting that there are other unexplained mechanisms[22-24]. In addition to the higher odds for KS in males, a striking, but incidental finding in the current study is the CD4 T-cell dependent difference in KS risk between males and females. KS prevalence in females appeared to be more sensitive to changes in CD4 T-cell count changes, with a significantly lower risk for KS occurring between CD4 T-cell counts of 200-500 cell/ $/ \mathrm{mm}^{3}$. In contrast, for advanced immunosuppression (CD4 T-cell count $<200$ cells $/ \mathrm{mm}^{3}$ ) or normal CD4 T-cell count (above 500 $\mathrm{cell} / \mathrm{mm}^{3}$ ); the difference was not significant. To the best of our knowledge, this is the first study to describe sex-based differences in the association between CD4 T-cell and KS prevalence. Sex-based differences in the association between CD4 T-cell and disease severity has however been reported in other diseases[25, 36]. This finding needs to be verified in other populations and its implications for KS prevention examined.

The findings of this study need to be interpreted in the context of its limitations. First, this is a singlecenter study from a tertiary health facility which is a center for excellence for HIV care. The study population may, therefore, differ from those of patients initiating HIV care in other facilities in Nigeria. Another limitation is that not all cases of KS were histologically confirmed, which may lead to misclassification and errors in the estimate of KS prevalence. Also, since routinely collected clinical data were evaluated, unmeasured factors such as training of health providers may have led to increased recognition and documentation of KS cases. Although rare, patients with visceral KS alone may have been missed due to lower resources for diagnostic testing such as CT scans, bronchoscopy, and endoscopy leading to underestimation of KS prevalence. Also, since the study was limited to adults initiating HIV care, the results may not provide a reliable estimate of changes in the prevalence of HIVassociated KS in the community.

Despite these limitations, a key strength of this study is its large sample size and 12-year time span which provided sufficient power to precisely assess KS prevalence and evaluate changes over significant periods of ART expansion in Nigeria. While routinely collected clinical data were utilized, the JUTH HIV clinic has rigorous protocols to maintain a high-quality database, which is routinely used for research[13, 20, 37]. Recent funding support from the US National Institute for Health has also supported the validation of cancer cases within the database. Lastly, although the study was conducted among patients in just one clinic, the age, sex, and CD4 T-cell count distribution of patients in this cohort were similar to reports from other large HIV cohort across Nigeria[27, 38].

The findings from this study have important implications for HIV care providers, researchers, and policymakers. Despite the relatively low KS prevalence among Nigerians initiating HIV care, KS prevalence has not appreciably declined (even since the 1990s) despite the expansion of ART coverage. Considering its large HIV population, Nigeria is an important contributor to the global burden of HIV-associated KS. In 
addition to interventions aimed at reducing HIV transmission, those targeted at timely HIV diagnosis and linkage to care may be most effective in reducing the prevalence of KS among patients initiating HIV care. This includes increased access to HIV testing, including home-based testing,[39] to aid early HIV diagnosis. Currently, only about $37 \%$ of Nigerians have access to quality HIV testing services, which is an essential first step along the cascade of HIV care and treatment[9]. Following HIV diagnosis, innovative and effective ways to link newly diagnosed patients to access care need to be identified and deployed.

In conclusion, despite increases in ART coverage, this study did not find a decline in the KS prevalence among adults initiating HIV care in Jos, Nigeria. Even in the most recent era of HIV care (2014-2017), over $50 \%$ of patients had advanced HIV disease[8] at first presentation, putting them at high risk for KS.

Strategies to aid early HIV diagnosis and entry into care in low-resource and high HIV burdened countries are needed as this may present the most effective approach to prevent HIV-associated KS globally.

\section{Abbreviations}

AIDS: Acquired Immune Deficiency Syndrome

ART: Antiretroviral therapy

HIV: Human Immunodeficiency Virus

IQR: Interquartile range

SD: Standard deviation

SSA: sub-Saharan Africa

WHO: World Health Organization

\section{Declarations}

Ethics approval and consent to participate: We obtained Institutional Review Board approval from the JUTH Research and Ethics Committee (JUTH/DCS/ADM/127/XXVII/715) and the study was ruled exempt by the Institutional Review Board of Northwestern University, Chicago, USA (STU00209667). Permission for secondary data use was obtained from APIN regulatory affairs committee, Nigeria (ARA/2018/001) and the Havard T. Chan School of Public Health. All study participants in the Harvard/APIN PEPFAR program provided informed consent for use of their data and/or samples for research.

Consent for publication: Not applicable

Availability of data and materials: All study data will be made available by the first author upon request.

Competing interests: All authors declare no competing interest. 
Funding: This work was supported by the following grants: US Department of Health and Human Services, Health Resources and Services Administration (U51HA02522), the Centers for Disease Control and Prevention (CDC) through a cooperative agreement with APIN (PS 001058), National Cancer Institute Grant Office (1U54CA221205-01), John E. Fogarty International Center for Advanced Study in the Health Sciences, Grant (5D43TW009575-05). The contents of this work are solely the responsibility of the authors and do not necessarily represent the official views of funding agencies.

\section{Authors' contributions:}

MOA had full access to all study data and takes responsibility for the accuracy of the data. The concept and design of the study were by MOA, LAB, CA, LRH, LH, and RLM. Data acquisition was by MOA, OAS, PAA, OA, NYS, SSG, and SAS. Data analysis and interpretation were by MOA, LAB, CA, LRH, PAA, and LH. The initial draft of the manuscript was done by MOA. All authors contributed to the initial draft, reviewed the manuscript, approved the final version, and agree to be accountable for all aspects of the work.

Acknowledgments: We acknowledge the contribution of Mohammed Lamorde MD, Ph.D. and Adovich Rivera MD, Msc for helping review this manuscript. We are also grateful to Bola Olatunde for assisting with data management.

\section{References}

1. Bray F, Ferlay J, Soerjomataram I, Siegel RL, Torre LA, Jemal A: Global cancer statistics 2018 : GLOBOCAN estimates of incidence and mortality worldwide for 36 cancers in 185 countries. CA: $A$ Cancer Journal for Clinicians 2018, 68(6):394-424.

2. Semeere A, Wenger M, Busakhala N, Buziba N, Bwana M, Muyindike W, Amerson E, Maurer T, McCalmont T, LeBoit $\mathrm{P}$ et al: A prospective ascertainment of cancer incidence in sub-Saharan Africa: The case of Kaposi sarcoma. Cancer medicine 2016, 5(5):914-928.

3. Akanbi MO, Taiwo BO, Achenbach CJ, Ozoh OB, Obaseki DO, Sule H, Agbaji OO, Ukoli CO: HIV Associated Chronic Obstructive Pulmonary Disease in Nigeria. Journal of AIDS \& clinical research 2015, 6(5).

4. Maskew M, Fox MP, van Cutsem G, Chu K, MacPhail P, Boulle A, Egger M, Africa fIS: Treatment Response and Mortality among Patients Starting Antiretroviral Therapy with and without Kaposi Sarcoma: A Cohort Study. PLoS One 2013, 8(6):e64392.

5. Rohner E, Kasaro M, Msadabwe-Chikuni SC, Stinson K, Mohamed Z, Tweya H, Egger M, Bohlius J: Treatment and outcome of AIDS-related Kaposi sarcoma in South Africa, Malawi and Zambia: an international comparison. Pan Afr Med J 2017, 28:261.

6. Gwaram AB, Yusuf MS: Clinical presentation and treatment outcome of HIV associated Kaposi sarcoma in a tertiary health centre in Nigeria. The Journal of Medical Research 2016, 2(4):110-113.

7. Schneider JW, Dittmer DP: Diagnosis and Treatment of Kaposi Sarcoma. American journal of clinical dermatology 2017, 18(4):529-539. 
8. Antinori A, Coenen T, Costagiola D, Dedes N, Ellefson M, Gatell J, Girardi E, Johnson M, Kirk O, Lundgren $\mathrm{J}$ et al: Late presentation of HIV infection: a consensus definition. HIV Medicine 2011, 12(1):61-64.

9. National Agency for the control of AIDS (NACA). National HIV and AIDS Strategic Plan 2017-2021. In. Edited by National Agency for the control of AIDS (NACA) Nigeria.; 2017.

10. Joint United Nations Programme on HIV/AIDS., World Health Organization.: AIDS epidemic update. In.

11. Uldrick TS, Whitby D: Update on KSHV-Epidemiology, Kaposi Sarcoma Pathogenesis, and Treatment of Kaposi Sarcoma. Cancer letters 2011, 305(2):150-162.

12. Ogoina D, Onyemelukwe G, Musa BO, Babadoko A: Seroprevalence and determinants of human herpes virus 8 infection in adult Nigerians with and without HIV-1 infection. Afr Health Sci 2011, 11(2):158-162.

13. Agaba P, Meloni S, Sule H, Agbaji O, Ekeh P, Job G, Nyango N, Ugoagwu P, Imade G, Idoko J et al: Patients who present late to HIV care and associated risk factors in Nigeria. HIV Medicine 2014, 15(7):396-405.

14. Akarolo-Anthony SN, Maso LD, Igbinoba F, Mbulaiteye SM, Adebamowo CA: Cancer burden among HIV-positive persons in Nigeria: preliminary findings from the Nigerian AIDS-cancer match study. Infect Agent Cancer 2014, 9(1):1.

15. Nigeria. HIV Country Profile [http://www.who.int/hiv/data/Country_profile_Nigeria.pdf?ua=1]

16. Frank TD, Carter A, Jahagirdar D, Biehl MH, Douwes-Schultz D, Larson SL, Arora M, Dwyer-Lindgren L, Steuben KM, Abbastabar $\mathrm{H}$ et al: Global, regional, and national incidence, prevalence, and mortality of HIV, 1980\&\#x2013;2017, and forecasts to 2030, for 195 countries and territories: a systematic analysis for the Global Burden of Diseases, Injuries, and Risk Factors Study 2017. The Lancet HIV 2019, 6(12):e831-e859.

17. Semeere AS, Busakhala N, Martin JN: Impact of Antiretroviral Therapy on the Incidence of Kaposi's Sarcoma in Resource-rich and Resource-limited Settings. Current opinion in oncology 2012, 24(5):522-530.

18. Kolawole GO, Gilbert HN, Dadem NY, Genberg BL, Agaba PA, Okonkwo P, Agbaji OO, Ware NC: Patient Experiences of Decentralized HIV Treatment and Care in Plateau State, North Central Nigeria: A Qualitative Study. AIDS Res Treat 2017, 2017:2838059-2838059.

19. Odekunle FF, Odekunle RO: The impact of the US president's emergency plan for AIDS relief (PEPFAR) HIV and AIDS program on the Nigerian health system. Pan Afr Med J 2016, 25:143.

20. Hamel DJ, Sankale JL, Samuels JO, Sarr AD, Chaplin B, Ofuche E, Meloni ST, Okonkwo P, Kanki PJ: Building laboratory capacity to support HIV care in Nigeria: Harvard/APIN PEPFAR, 2004-2012. African journal of laboratory medicine 2015, 4(1).

21. Federal Ministry of Health Nigeria.: National Guidelines For HIV And AIDs Treatment And Care In Adolescents And Adults. Nigeria; 2010. http://www.who.int/hiv/pub/guidelines/nigeria_art.pdf. Accessed 2 Feb 2017. In.; 2010. 
22. Rohner E, Valeri F, Maskew M, Prozesky H, Rabie H, Garone D, Dickinson D, Chimbetete C, LumanoMulenga P, Sikazwe I et al: Incidence rate of Kaposi sarcoma in HIV-infected patients on antiretroviral therapy in Southern Africa: a prospective multicohort study. J Acquir Immune Defic Syndr 2014, 67(5):547-554.

23. Bohlius J, Valeri F, Maskew M, Prozesky H, Chimbetete C, Lumano-Mulenga P, Garone D, Gsponer T, Egger M: Incidence of Kaposi Sarcoma in HIV-infected patients - a prospective multi-cohort study from Southern Africa. Infectious Agents and Cancer 2012, 7(1):020.

24. Semango GP, Charles RM, Swai Cl, Mremi A, Amsi P, Sonda T, Shao ER, Mavura DR, Joosten LAB, Sauli E et al: Prevalence and associated risk factors for Kaposi's sarcoma among HIV-positive patients in a referral hospital in Northern Tanzania: a retrospective hospital-based study. BMC cancer 2018, 18(1):1258.

25. Tipton AJ, Sullivan JC: Sex differences in T cells in hypertension. Clin Ther 2014, 36(12):1882-1900.

26. Beral V, Bull D, Darby S, Weller I, Came C, Beecham M, Jaffe H: Risk of Kaposi's sarcoma and sexual practices associated with faecal contact in homosexual or bisexual men with AIDS. The Lancet 1992, 339(8794):632-635.

27. Chang CA, Meloni ST, Eisen G, Chaplin B, Akande P, Okonkwo P, Rawizza HE, Tchetgen Tchetgen E, Kanki PJ: Tuberculosis Incidence and Risk Factors Among Human Immunodeficiency Virus (HIV)Infected Adults Receiving Antiretroviral Therapy in a Large HIV Program in Nigeria. Open forum infectious diseases 2015, 2(4):ofv154-ofv154.

28. Rubin DB: Inference and missing data. Biometrika 1976, 63(3):581-592.

29. Hontelez JAC, Tanser FC, Naidu KK, Pillay D, Bärnighausen T: The Effect of Antiretroviral Treatment on Health Care Utilization in Rural South Africa: A Population-Based Cohort Study. PLoS One 2016, 11(7):e0158015-e0158015.

30. Luma HN, Jua P, Donfack O-T, Kamdem F, Ngouadjeu E, Mbatchou HB, Doualla M-S, Mapoure YN: Late presentation to HIV/AIDS care at the Douala general hospital, Cameroon: its associated factors, and consequences. BMC Infectious Diseases 2018, 18(1):298.

31. leDEA ART Cohort Collaborations., Avila D, Althoff KN, Mugglin C, Wools-Kaloustian K, Koller M, Dabis F, Nash D, Gsponer T, Sungkanuparph S et al: Immunodeficiency at the start of combination antiretroviral therapy in low-, middle, and high-income countries. Journal of acquired immune deficiency syndromes (1999) 2014, 65(1):e8-e16.

32. Centers for Disease C: Kaposi's sarcoma and Pneumocystis pneumonia among homosexual men-New York City and California. MMWR Morb Mortal Wkly Rep 1981, 30(25):305-308.

33. Rohner E, Wyss N, Heg Z, Faralli Z, Mbulaiteye SM, Novak U, Zwahlen M, Egger M, Bohlius J: HIV and human herpesvirus 8 co-infection across the globe: Systematic review and meta-analysis. Int $J$ Cancer 2016, 138(1):45-54.

34. Liu Z, Fang Q, Zuo J, Minhas V, Wood C, Zhang T: The world-wide incidence of Kaposi's sarcoma in the HIV/AIDS era. HIV Medicine 2018, 19(5):355-364. 
35. Friedman-Kien AE: Disseminated Kaposi's sarcoma syndrome in young homosexual men. Journal of the American Academy of Dermatology 1981, 5(4):468-471.

36. Aldridge J, Pandya JM, Meurs L, Andersson K, Nordström I, Theander E, Lundell A-C, Rudin A: Sexbased differences in association between circulating $T$ cell subsets and disease activity in untreated early rheumatoid arthritis patients. Arthritis Research \& Therapy 2018, 20(1):150.

37. Meloni ST, Chang CA, Eisen G, Jolayemi T, Banigbe B, Okonkwo PI, Kanki PJ: Long-Term Outcomes on Antiretroviral Therapy in a Large Scale-Up Program in Nigeria. PLoS One 2016, 11(10):e0164030.

38. Dalhatu I, Onotu D, Odafe S, Abiri O, Debem H, Agolory S, Shiraishi RW, Auld AF, Swaminathan M, Dokubo K et al: Outcomes of Nigeria's HIV/AIDS Treatment Program for Patients Initiated on Antiretroviral Treatment between 2004-2012. PLoS One 2016, 11(11):e0165528.

39. Ganguli I, Bassett IV, Dong KL, Walensky RP: Home testing for HIV infection in resource-limited settings. Curr HIV/AIDS Rep 2009, 6(4):217-223.

\section{Figures}

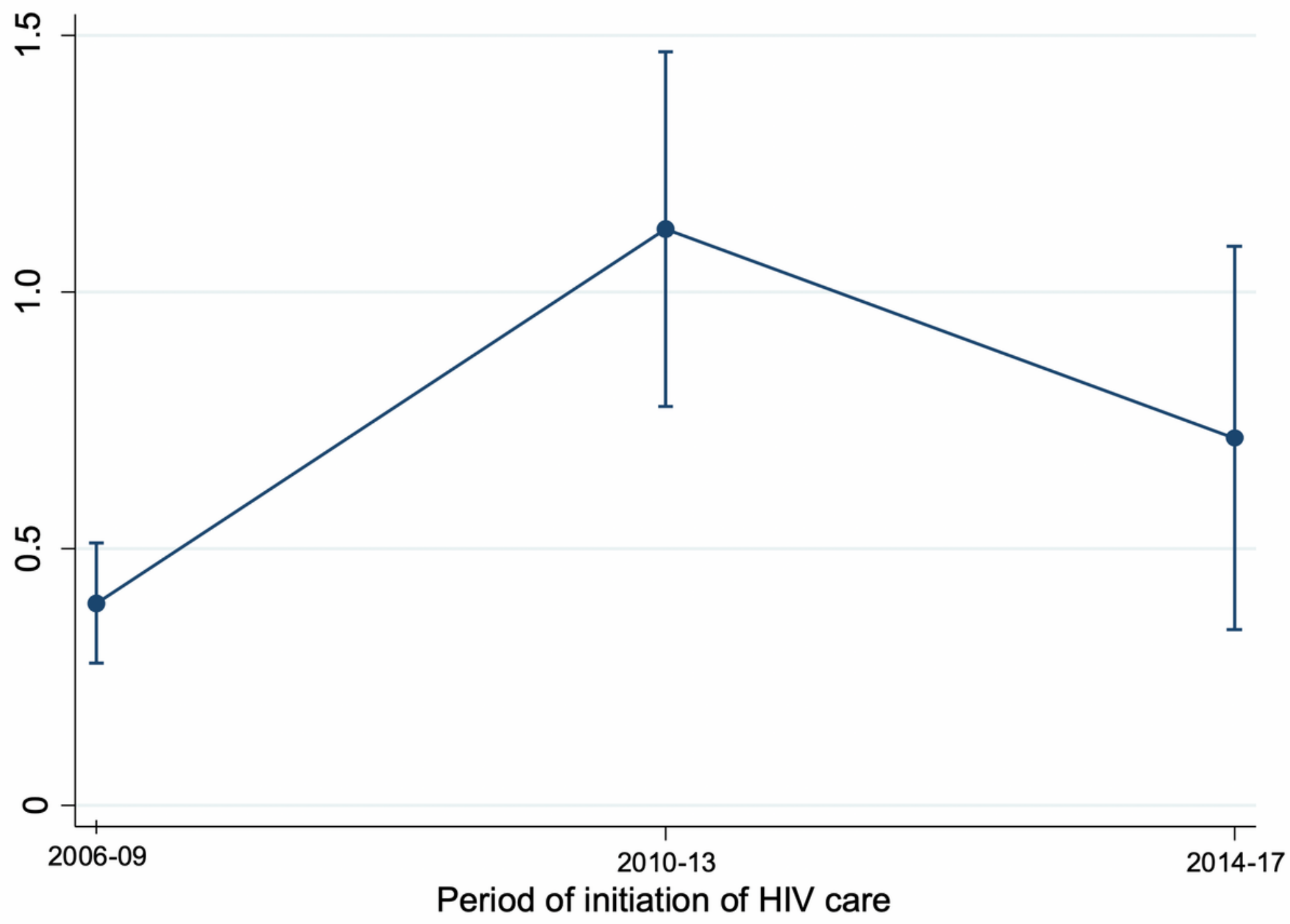

Figure 1 
Trends in predicted prevalence of Kaposi sarcoma at HIV care initiation among adults at the Jos University Teaching Hospital HIV Clinic Jos, Nigeria. (Figure obtained from margin plot of the logistic regression model adjusted for age and sex. Bars indicate 95\% confidence intervals).
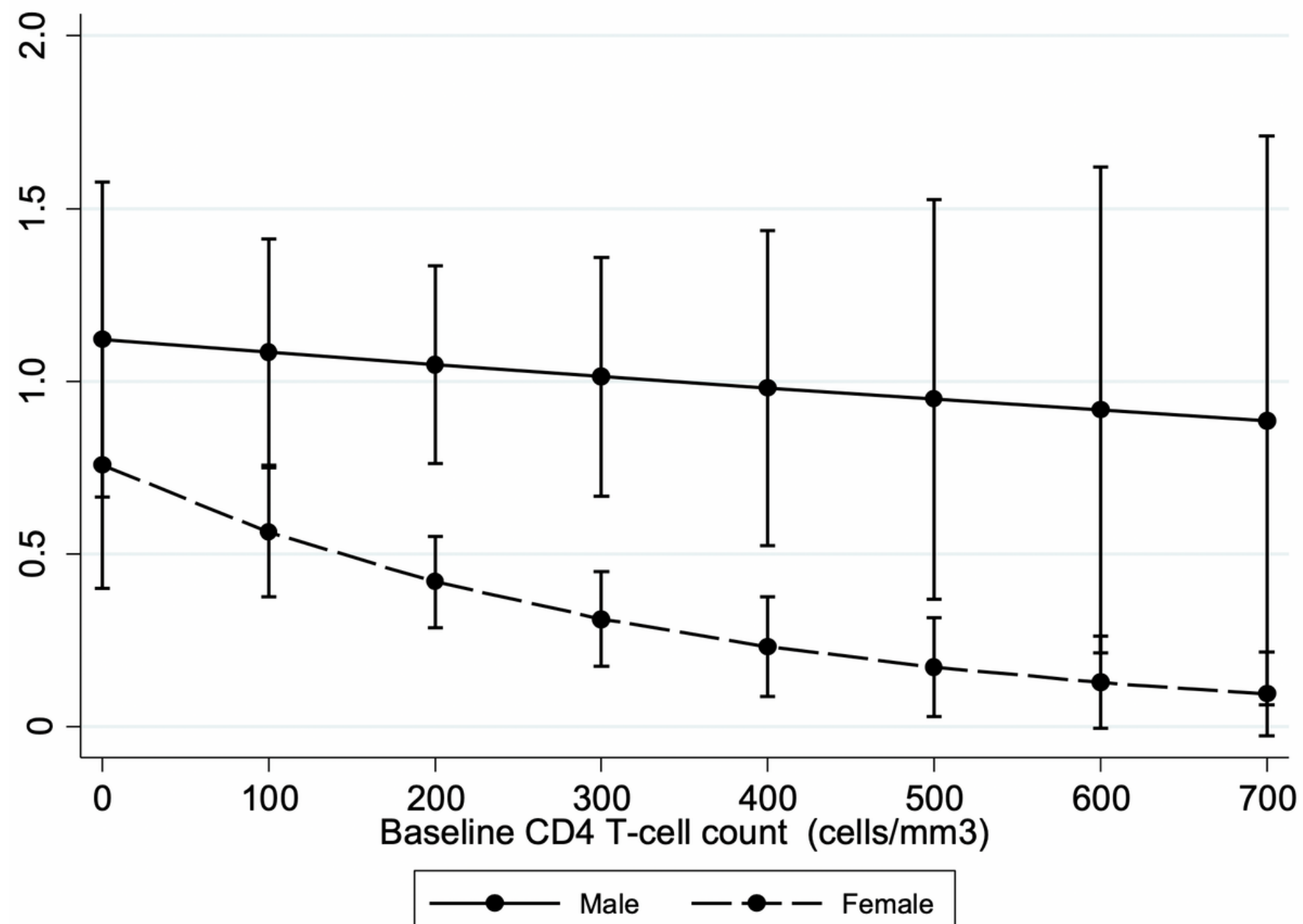

Figure 2

Predicted prevalence of Kaposi sarcoma at HIV care initiation in adults at the Jos University Teaching Hospital HIV Clinic Jos, Nigeria (2006-2017) stratified by CD4-T Cell count at HIV care initiation and sex. (Figure from margin plot of sex by CD4 T-cell count. Bars show 95\% confidence intervals) 